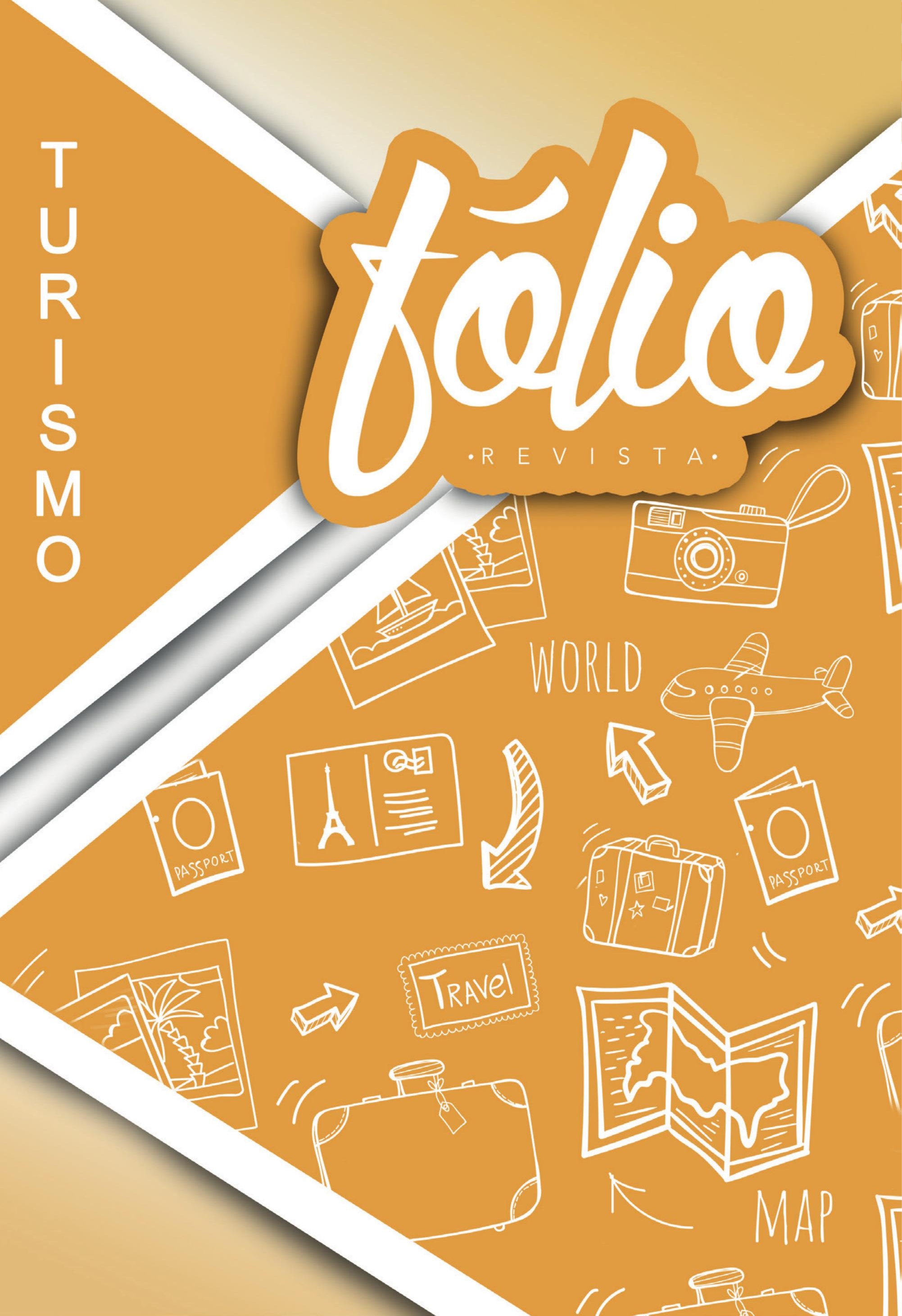




\title{
Olhares sobre Porto Alegre: o discurso oficial e a visão dos turistas
}

\section{Views about Porto Alegre: official speech and vision of tourists}

\author{
MACHADO, Andréia Ramos ${ }^{1}$
}

\section{Resumo}

O objetivo deste artigo é identificar a imagem de Porto Alegre/RS, construída pelo órgão oficial do Turismo na cidade e traçar um paralelo com o olhar do turista na mídia digital, analisando os discursos de alguns atributos turísticos da cidade no Portal do Turista e as observações dos visitantes no Tripadvisor. Para tanto, será utilizada a Análise de Discurso como aporte teórico e metodológico. Será estabelecida a relação das cidades e o Turismo. Após, especifica-se a metodologia de análise e, em seguida, reconhece-se como Porto Alegre tornou-se cidade e se constituiu na história com suas tradições e cultura. Por fim, passa-se à análise dos discursos sobre dois importantes pontos turísticos da cidade. Ao final o que se pode identificar é que, tanto no aspecto oficial quanto na visão do turista, as atrações são importantes pelo seu aspecto cultural, pela relação da cidade com a cultura.

Palavras-chave: Comunicação Social. Cidades. Cultura. Turismo.

\section{Abstract}

The objective of this article is to identify the image of Porto Alegre / RS, constructed by the official tourism agency in the city and draw a parallel with the tourist 's perspective in the digital media, analyzing the speeches of some tourist attributes of the city in the Tourist Portal And visitors' comments on Tripadvisor. For this, the Discourse Analysis will be used as a theoretical and methodological contribution. The relationship of cities and tourism will be established. Afterwards, it specifies the methodology of analysis and then it is recognized as Porto Alegre became city and was constituted in history with its traditions and culture. Finally, we proceed to the analysis of the discourses on two important sights of the city. In the end what can be identified is that, both in the official aspect and in the view of the tourist, the attractions are important because of their cultural aspect, the relation of the city to the culture.

Keywords: Social Communication. Cities. Culture. Tourism.

\footnotetext{
1 Mestra em Comunicação Social pela PUCRS. MBA em Marketing pela Fundação Getúlio Vargas. Graduação em Publicidade e Propaganda pela Unisinos/RS e em Gestão do Turismo pela Universidade Católica de Brasília/DF. Consultora de Comunicação e Marketing. deiaramos@ nol.com.br.
} 


\section{Introdução}

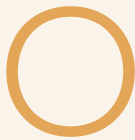

bservar as cidades pode ser muito interessante por mais simples que possa parecer. A cidade se constroi em um espaço tal qual um projeto arquitetônico, mas sua essência só é absorvida no decorrer de longos anos de contemplação e vivência. Em cada esquina existe mais do que os olhos podem enxergar, uma nova cena a ser descoberta.

Sabe-se que a imagem de um ambiente é o resultado de um duplo olhar: do observador e o do próprio meio. Segundo Linch (1960, p. 16) "o meio ambiente sugere distinções e relações, e o observador - com grande adaptação e à luz dos seus objetivos próprios - seleciona, organiza e dota de sentido aquilo que vê". Desta maneira, a imagem de um dado local pode modificar substancialmente entre observadores diferentes.

Esta imagem da cidade é construída então, por uma gama diversificada de elementos que contemplam história, cultura e imaginário. O Turismo se utiliza destes princípios para transformar o conjunto de construções, ruas, praças que compõem uma cidade em um "produto" turístico.

O turismo urbano procura absorver o que é peculiar em cada cidade e descobre uma gama de possibilidades para "seduzir" o turista. "O uso da cidade como espaço de integração de produtos turísticos responde ao crescente interesse pelas questões culturais e patrimoniais, como também por práticas de usos diferenciados dos setores espaciais" (CATROGIOVANNI, 2000, p.08).

Atualmente, muito desta divulgação das cidades como um recurso turístico acontece na mídia digital. Sites, blogs, redes sociais são utilizados para divulgar o que cada local oferece de atrações para quem procura informações turísticas. Quando a cidade não possui algum atributo principal, natural ou construído, cabe aos envolvidos com o Turismo procurarem divulgar o que seria interessante para atrair os viajantes.

Assim acontece com Porto Alegre, a capital do estado do Rio Grande do Sul, ponto meridional do Brasil. A cidade não possui todo o potencial turístico comparado com outras capitais brasileiras, principalmente com as conhecidas belezas naturais dos litorais do país. Sendo assim, é necessário absorver o que existe de impactante em seus monumentos, pontos culturais, hábitos e tradições que possam atrair os turistas.

Neste artigo, o objetivo é identificar a imagem de Porto Alegre construída pelo órgão oficial do Turismo na cidade e traçar um paralelo com o olhar do turista na mídia digital, analisando os discursos de alguns atributos turísticos da cidade no Portal do Turista ${ }^{1}$ e as observações dos visitantes no Tripadvisor ${ }^{2}$. Para tanto, será utilizada a Análise de Discurso como aporte teórico e metodológico, por meio das premissas de Patrick Charaudeau.

Inicialmente, será estabelecida a relação das cidades com o Turismo, identificando como um local se constitui como turístico e os diferentes olhares sobre ele. Em seguida especifica-se a metodologia de análise deste estudo e as principais premissas utilizadas pela AD para analisar o discurso das mídias.

Após, reconhece-se como Porto Alegre tornou-se cidade e se constituiu na história com suas tradições e cultura, a fim de contextualizar a situação de produção dos discursos a serem analisados posteriormente.

Por fim passa-se à análise dos discursos sobre dois importantes pontos turísticos da cidade, no Portal do Turista que se encontra no site oficial da Secretaria de Turismo da Prefeitura de Porto Alegre contrapondo com as três últimas avaliações feitas pelos visitantes de fora do estado do Rio Grande do Sul no site do Tripadvisor sobre os mesmos locais.

\section{As cidades e o turismo}

Após a revolução industrial e a globalização econômica, as cidades tem se tornado espaços importantes para o Turismo, concentrando em um mesmo roteiro atrações, serviços, simbologias culturais e eventos, o que tem possibilitado uma

\footnotetext{
1 Portal do Turista é uma sessão do site da Secretaria de Cultura de Porto Alegre e está disponível em http://www.portoalegre. travel/site/home.php.

$2 \bigcirc$ Tripadvisor é um dos maiores sites de viagens do mundo e oferece dicas de viajantes e opções de viagem e de recursos de planejamento. Está disponível em https://www.tripadvisor.com.br/.
} 
reestruturação de lugares, serviços e revitalização de prédios e praças que podem representar a expressividade histórica e simbólica da localidade.

Logo, quando se chega a alguma cidade a procura de um determinado local ou evento, aproveita-se o tempo para conhecer o que mais a cidade "tem a oferecer". Segundo Wainberg (2000) é possível pensar a cidade com uma atração em si, um conjunto de diversos níveis de lazer ofertados. O autor afirma que a cidade deve ser vista como uma fala a ser interpretada por quem nela transita. Seus segredos são desvendados com a exploração de cada canto, como se fosse uma obra de arte viva, onde seus autores são os indivíduos que ali passam.

Esses autores anônimos complementam o círculo urbano que confere um status à cidade de hospitalidade, receptividade ou aspereza de acordo com a maneira que recebem os visitantes. Tudo isso está inserido no processo histórico da cidade. A cada momento descobrem-se novos elementos que os sentidos ainda não haviam captados. Novas visões, novos odores, novos gostos. "A cidade é o que é visto, mas mais ainda, o que pode ser sentido" (CASTROGIOVANNI, 2000, p. 25).

Por conseguinte, os visitantes podem ter outra impressão sobre uma cidade comparando a opinião dos habitantes do local. Então, não é possível determinar uma única imagem da cidade, pois cada local pode ter uma variada avaliação de acordo com o conhecimento e sensibilidade de cada observador. Mas é possível aproveitar-se destas múltiplas visões e entender a cidade como uma teia de sentidos que a compõe como componente turístico.

De acordo com Castrogiovanni (2000) a identidade de uma cidade está ligada as suas peculiaridades, devendo possuir algum significado para quem as observa, seja estético ou simbólico. E a constituição da cidade como produto turístico também depende do observador e sua capacidade de percebê-la como tal.

Além do patrimônio histórico da cidade, edificações importantes do ponto de vista da arquitetura, existem outros elementos que complementam a atratividade do local. Para que o turista construa uma boa imagem da cidade não é somente necessário ter belas atrações para ver. Pre- cisa que a atividade turística seja bem regulamentada e organizada para que o turista sinta prazer na visita, afinal o turismo é uma atividade de lazer.

Como já afirmava John Urry em 1990, as cidades são escolhidas para serem contempladas porque foi gerada uma expectativa que envolve sentidos diferentes do que nos deparamos quando vivemos no local. Esta expectativa é, hoje em dia, construída por diversos canais: televisão, cinema, revistas, mas principalmente pela internet. Tanto os órgãos públicos investem na divulgação das cidades como os próprios aparelhos turísticos. Todas estas publicações na mídia auxiliam a construir e reforçar o olhar do turista sobre aquele roteiro.

Com o surgimento das redes sociais, outro fator importante nesta construção imagética são os comentários e depoimentos de quem já visitou os lugares. Atualmente o turista, antes de tomar qualquer decisão sobre o roteiro de viagem, consulta os comentários dos turistas e suas avaliações nas postagens relativas ao lugar de seu interesse.

Enfim, para se analisar a comunicação turística e a imagem das cidades na mídia é importante perceber como está construído o discurso oficial e de que maneira ele é percebido pelos destinatários, já que ambos os fatores são determinantes na imagem construída pelo turista sobre aquela cidade.

\section{Análise do discurso do turismo em Porto Alegre}

\section{A análise de discurso e o discurso das mídias}

A Análise do Discurso das mídias é realizada a partir de um corpus de artefatos culturais empíricos disseminados por ocorrências comunicacionais. Eles podem ser anúncios de publicidade, jornais, programas de televisão ou de rádio, publicações na web, entre outros. Quando se analisa um texto de comunicação por meio da análise de discurso, identificando-o como parte integrante de um contexto determinado é que se diz que foi analisado o discurso. Os participantes deste ato de comunicação passam a ser considerados su- 
jeitos do ato linguageiro.

A AD proporciona que o analista compreenda o que cada discurso quer "falar" e de que modo ele o faz, tendo assim uma interpretação mais rica do texto. $\bigcirc$ discurso resulta de uma combinação das circunstâncias da produção da fala com a maneira pela qual se comunica. Assim "todo discurso, antes de representar o mundo, representa uma relação ou representa o mundo ao representar uma relação. Isso também é verdade para o discurso de informação" (CHARAUDEAU, 2014, p. 42).

A partir disto, reconhece-se que os acontecimentos não podem ser informados somente de maneira factual é necessário que a informação seja divulgada utilizando-se de estratégias a fim de interessar ao maior número de indivíduos. Assim, as mídias recorrem a diversos tipos de estratégias em seus discursos para atingir seus objetivos.

Considerando o discurso das mídias, pode-se afirmar, segundo Charaudeau (2014), que as mídias detêm uma parte do poder social. $\bigcirc$ discurso da informação midiática coloca em cena, de maneira variável e com diferentes consequências, efeitos de autenticidade, de probabilidade e de dramatização.

Neste enredo da comunicação midiática é estabelecida uma relação entre duas instâncias: uma de produção e outra de recepção, compreendendo diversos atores. Todos contribuem para a criação da enunciação do discurso midiático, cuja intenção corresponde a um projeto comum a esses atores envolvidos no processo e que representa a ideologia da organização da informação (CHARAUDEAU, 2009). Na relação entre estas duas instâncias se estabelecem contratos de comunicação midiática, permeadas por modos de organização do discurso e visadas situacionais.

\section{Metodologia}

A fim de identificar a imagem de Porto Alegre construída pelo órgão oficial do Turismo na cidade e traçar um paralelo com o olhar do turista na mídia digital, serão analisados os discursos de alguns pontos turísticos da cidade publicados na sessão "O que visitar" do Portal do Turista, administrado pela prefeitura da cidade e as observa- ções dos visitantes no site Tripadvisor.

Para o corpus deste estudo foram escolhidos dois dos principais locais turísticos de Porto Alegre: o Brique da Redenção e a Usina do Gasômetro. Além disso, serão selecionados os três últimos depoimentos de turistas de localidades fora do estado do Rio Grande do Sul, sobre cada um dos locais selecionados publicados nas avaliações no site Tripadvisor.

Após a escolha dos textos a serem explorados, passa-se para análise discursiva. Começa-se por observar o modo de construção do texto, a estruturação e seu modo de circulação assim como os elementos que constituem a construção dos sentidos. Busca-se identificar quem são os sujeitos dos discursos, as escolhas que se fez e as estratégias utilizadas, o que querem dizer com a mensagem e para quem ela se destina. Desta maneira, ao final de cada análise, pretende-se identificar os contratos estabelecidos com o turista e as diferenças ou similaridades entre os dois tipos de discurso analisados.

\section{Contexto situacional}

A cidade de Porto Alegre tem como data oficial de fundação 26 de março de 1772, com a criação da Freguesia de São Francisco do Porto dos Casais. Um ano mais tarde seu nome foi alterado para Nossa Senhora da Madre de Deus de Porto Alegre. Mas antes disso, o povoamento da região começou a acontecer com a chegada de 60 casais portugueses açorianos, que vinham se instalar nas Missões que estava sendo entregue ao governo português devido ao Tratado de Madri. Como a demarcação das terras demorou a acontecer, os portugueses permaneceram onde tinham desembarcado. Um ano após a fundação da cidade, Porto Alegre se tornou a capital da capitania. Algum tempo depois, já constituída como cidade importante para a região, começou a receber imigrantes de todo o mundo, em particular alemães, italianos, espanhois, africanos, poloneses, judeus e libaneses. Esta característica de possuir múltiplas culturas faz de Porto Alegre, uma cidade multicultural, plural. A influência destas culturas se observa nas construções em determinados bairros, on- 
de se estabeleceram os imigrantes.

Porto Alegre é ponto estratégico dentro do MERCOSUL e centro geográfico das principais rotas do Cone Sul. Para quem chega às terras gaúchas, Porto Alegre é a porta de entrada para os principais atrativos turísticos da região. A cidade conta, atualmente, com aproximadamente 1,5 Ml de habitantes. Em 2017 assumiu uma nova administração na cidade que está com inúmeras obras sem andamento e com grandes dívidas administrativas.

\section{O discurso do Turismo em Porto Alegre}

A partir deste momento, passa-se para a análise dos textos relativos aos pontos turísticos selecionados, no Portal do Turista e no Tripadvisor respectivamente. Os discursos a serem analisados serão reproduzidos na forma com que aparecem nos sites, assim, pretende-se permitir a legibilidade do conteúdo. Também serão disponibilizados os links para a consulta diretamente na mídia digital.

\section{O Brique da Redenção ${ }^{3}$ no Portal do Turista \\ Figura 1 - Brique da Redenção}

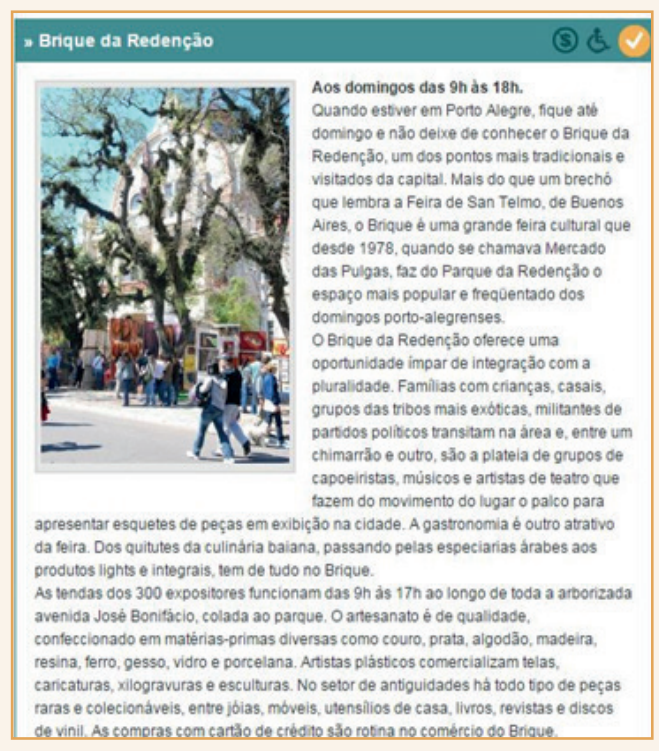

Fonte: Portal do Turista, Secretaria do Turismo de Porto Alegre 2017

3 Disponível em http://www.portoalegre.travel/site/onde_visitar. php. Acesso em 17 de fevereiro de 2017.
O discurso apresentado na figura 1 está organizado no modo descritivo. É possível reconhecer nele os três principais componentes deste formato de construção discursiva: nomear, situar e qualificar. O início do texto explica o que é o Brique, o situa como uma feira diferente da tão conhecida Feira de San Telmo na Argentina e a qualifica como uma grande feira multicultural. Neste procedimento discursivo a finalidade da situação de comunicação está em definir, explicar, incitar e contar.

Na encenação descritiva o sujeito não coloca o seu ponto de vista em relação ao seu interlocutor. Sendo assim, o sujeito enunciador (EUe), responsável pela fala, pode ser interpretado como sendo o mesmo sujeito que produz a fala (EUc). Segundo Charaudeau (2014, p. 50) "a partir disso, notamos que a noção de autor de uma frase não é uma noção clara, nem operante, pois, recobre um sujeito duplo: o EUe e o EUc".

Diante disso o sujeito comunicante e o enunciador seriam a Secretaria de Turismo da cidade, responsável pelo site. O sujeito destinatário (TUd) é aquele indivíduo que está em Porto Alegre, mas o discurso não deixa claro que o TUd é um turista a passeio, principalmente pela expressão "Quando estiver em Porto Alegre, fique até domingo". A cidade tem uma grande circulação de indivíduos que vem a trabalho ou em eventos, então, mesmo sendo um turista que não escolheu o roteiro pelo lazer, ele pode aproveitar seus momentos livres para conhecer Porto Alegre e seus atrativos.

Essa é uma das estratégias utilizadas neste discurso. O texto é construído de maneira a seduzir quem está a passeio e a trabalho. A estratégia de sedução fica evidente quando as atrações são descritas com expressões como: "grande feira cultural", "oportunidade ímpar", "tem de tudo no Brique", "toda arborizada" e "artesanato de qualidade". A visada utilizada neste discurso é a da incitação. O eu quer "mandar fazer", mas só pode incitar a fazer, fazendo o TUd acreditar que ele será o principal beneficiário do seu ato, de sua decisão de conhecer o Brique.

O contrato proposto ao TUd é o da pluralidade. Se o turista quer conhecer um lugar que tem muitas oportunidades de lazer e tem pouco tempo na cidade, que vá conhecer o Brique, onde irá 
encontrar produtos para comprar, artistas para admirar, iguarias para experimentar, entre tantas outras atrações no mesmo local. É uma atração que é boa para qualquer tipo de público.

\section{O Brique da Redenção ${ }^{4}$ no Tripadvisor.}

Figura 2 - Brique da Redenção no Tripadvisor

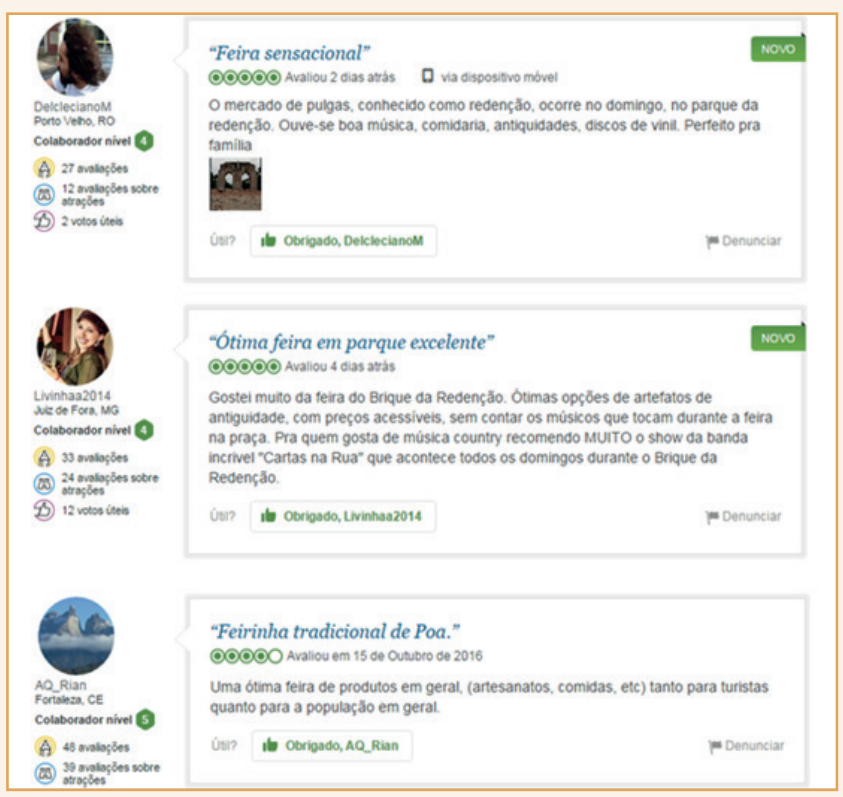

Fonte: Tripdvisor 2017

Os comentários analisados sobre o Brique da Redenção, conforme figura 2, têm modos de construção diferenciados. Enquanto o primeiro e o último utilizam o modo descritivo de organização do discurso onde identificam e qualificam de maneira objetiva, o segundo inicia o discurso dando sua opinião, posicionando-se em relação aos outros discursos como um relato, não somente uma avaliação, o que identifica o modo de organização como enunciativo.

Os sujeitos enunciadores (EUe) são os mesmos que produziram o discurso (EUc), totalmente identificáveis pelos perfis colocados ao lado dos comentários. Já os sujeitos destinatários são diferenciados nos três comentários. No primeiro, o discurso se dirige para quem viaja com a família,

4 Disponível em https://www.tripadvisor.com.br/Attraction_Reviewg303546-d4187463-Reviews-Brique_da_Redencao-Porto_Alegre_ State_of_Rio_Grande_do_Sul.html. Acesso em 17 de fevereiro de 2017. o segundo direciona seu comentário para quem gosta de música e o terceiro amplia o rol de destinatários para turistas e nativos.

Os três comentários se utilizam de estratégias de sedução e informação, procurando fazer com que os destinatários desejem conhecer o local e compartilhar da sensação que os autores tiveram ao conhecerem o Brique.

Além disso, cada discurso estabelece um contrato com o TUd proposto pelo EUc. No primeiro intitulado "Feira sensacional", o contrato proposto ao sujeito destinatário se assemelha ao proposto pelo discurso oficial. Vale à pena visitar a feira porque é multicultural e as atrações são diversificadas.

Já o segundo discurso nomeado como "Ótima feira em parque excelente", dá destaque para a cultura, dando ênfase para as antiguidades e a música. Propõe um contrato de que a atração é "ótima para quem aprecia atrações culturais". Não abrange tanto a pluralidade do local, mas o reconhece como um local cultural.

Enfim o terceiro, chamado de "Feirinha tradicional de POA" não aborda toda a amplitude cultural da feira. Apesar de chamar de "feirinha" no título, o EUc não a aborda como uma pequena feira, pelo contrário, reconhece depois que é uma feira de produtos em geral, sem depreciação. O contrato aqui é o de patrimônio cultural da cidade. A feira não é somente um ponto turístico, mas um hábito gaúcho que é compartilhado com quem visita a cidade.

\section{Usina do Gasômetro ${ }^{5}$ no Portal do Turismo Figura 3 - Usina do Gasômetro}

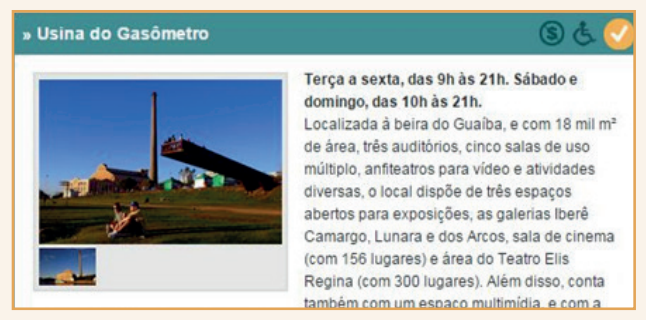

Fonte: Portal do Turista, Secretaria do Turismo de Porto Alegre
5 Disponível em : http://www.portoalegre.travel/site/onde_visitar.ph p?pagina $=4 \&$ bitPesquisa $=\&$ strNome $=\&$ strEndereco $=\& i d T i p o$ Atrativ $\mathrm{o}=\& \mathrm{bit} \mid \mathrm{mperdive} \mathrm{l}=\& \mathrm{bitSegundasPortoA}$ legre $=\&$ bitDiasChuva $=\& \mathrm{bit}$ ParaCriancas $=\& b i t V i s i t a A c e s s i b i l i d a d e=\& b i t E n t r a d a G r a t u i t a=\& s t r D$ estaque $=962,982,973,1378,1517$. Acesso em 17 de fevereiro de 2017. 
O discurso, apresentado na figura 3, está organizado no modo descritivo. Aos poucos descreve a história do local, a estrutura e aproveita para falar de outro ponto turístico de Porto Alegre que é o pôr do sol no Guaíba. Por ser a descrição de um local que pode ser verificado por qualquer sujeito além do sujeito enunciador, o discurso adquire um procedimento de "construção objetiva do mundo", qualificando sem exagero na estratégia de sedução.

Segundo Charaudeau (2014, p.139), "a encenação descritiva é ordenada pelo sujeito falante, o qual se torna um descritor". Sendo assim, como o texto não é assinado como sendo de autoria de alguém específico, o sujeito enunciador e o comunicante podem ser identificados como o Portal do Turista ou, subsequentemente, a Secretaria do Turismo de Porto Alegre.

O processo de produção de um discurso consiste em desenvolver uma mensagem direcionada a um TU destinatário (TUd). Neste discurso analisado, o interlocutor fabricado pelo EU como destinatário é o turista que visita Porto Alegre. A descrição é realizada de maneira a dar uma informação completa sobre o que e como aproveitar o local.

Apesar de utilizar adjetivos que valorizam a qualidade do local, como "famosa chaminé", "pontos mais tradicionais" e "famoso pôr do sol", o discurso não se utiliza de uma visada que busca incitar a fazer e sim da visada de informação, onde - EU quer "fazer saber", estando capacitado para isso, e o TU está na posição de "dever saber".

O contrato proposto pelo EU para o TUd e do qual ele espera uma contrapartida conivente, é o de "importância cultural". A descrição dá ênfase para a estrutura do local utilizando-se de atributos estruturais para ampliar sua importância. Ainda se conta com o pôr do sol para justificar uma visita ao local.

Nos três discursos dispostos na figura 4, no Tripadvisor, os sujeitos enunciadores dão a sua opinião de alguma maneira. Todos colocam seu ponto de vista em uma relação de influência sobre o interlocutor. Isto caracteriza o modo de organização dos discursos como sendo enunciativo. Fica evidente que a função do modo enunciativo usada na construção dos três discursos acima se refere ao comportamento alocutivo em relação ao interlocutor. Conforme Charaudeau (2014) o sujeito enunciador (EUe) coloca no discurso a sua posição e implica ao TUd um comportamento acional, uma reação.

\section{Usina do Gasômetro no Tripadvisor}

Figura 4 - Usina do Gasômetro no Tripadvisor

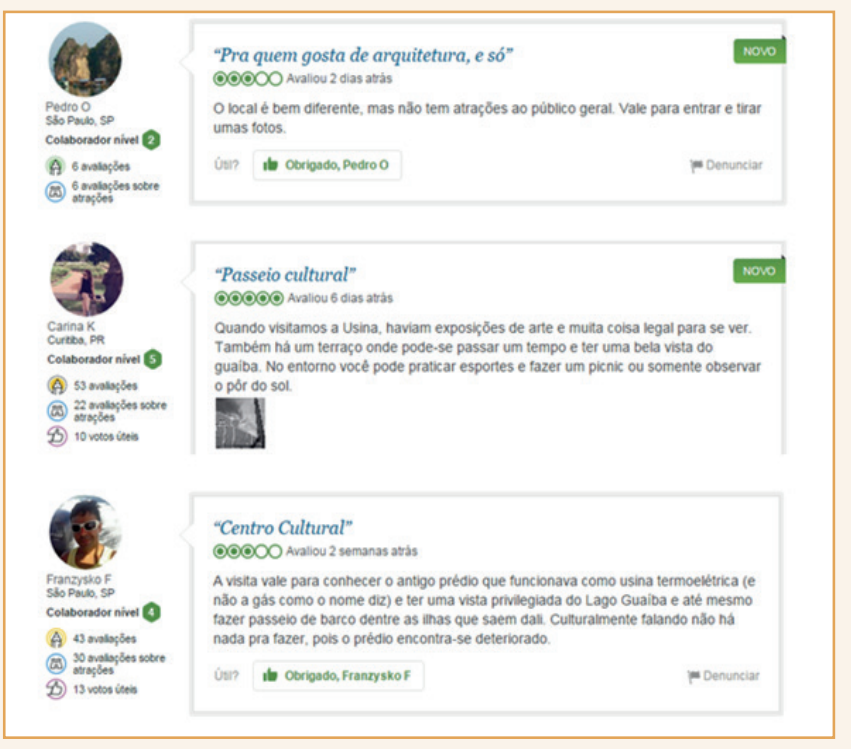

Fonte: Tripdvisor 2017

Como se tratam de opiniões, os sujeitos EUe e EUc são identificados como os autores expostos ao lado, no perfil do avaliador. O Tripadvisor utiliza este recurso para isentar-se de qualquer identificação com as avaliações, preservando-se de possíveis identificações como sujeito comunicante. As avaliações são de propósito e produção do autor identificado, sem influência do site.

O TUd proposto pelos três sujeitos comunicantes é o turista que visita Porto Alegre e que poderia se interessar em visitar o local.

Os contratos propostos aos sujeitos destinatários no primeiro e terceiro discursos são o de honestidade. Vale à pena visitar, mas não é uma atração excepcional. Já o segundo discurso propõe um contrato de "aproveitar a oportunidade".

6 Disponível em : http://www.portoalegre.travel/site/onde_visitar. php?pagina $=4 \&$ bitPesquisa $=\& \operatorname{strNome}=\&$ strEndereco $=\&$ idTipoAt rativo $=\&$ bitlmperdivel $=\&$ bitSegundasPortoAlegre $=\& b i t D i a s C h u v a$

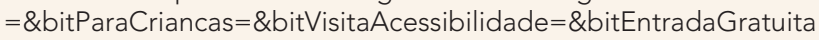
$=\&$ strDestaque $=962,982,973,1378,1517$. Acesso em 17 de fevereiro de 2017. 
Pode ser que o prédio e as atividades culturais não sejam o melhor, mas o turista pode aproveitar o local para fazer outras práticas diferenciadas.

\section{Síntese das Análises}

Retomando o que foi mencionado anteriormente, durante a análise do discurso, planejou-se identificar quem o texto faz falar, as escolhas e as estratégias utilizadas, o que cada um quis dizer com a mensagem e para quem ela se destinava. Sendo assim, ao final de cada análise, foi possível identificar os contratos estabelecidos com o turista.

As análises foram realizadas por ponto turísti$\mathrm{co}$, apresentando primeiramente o discurso oficial no site da Secretaria Municipal do Turismo de Porto Alegre, na parte do Portal do Turismo e após as três opiniões mais recentes no Tripadvisor, levando em conta a data de coleta dos depoimentos que foi em 17 de fevereiro 2017.

Com relação ao modo de organização, os discursos do portal oficial foram desenvolvidos descritivamente. Mesmo que apresentem alguns adjetivos para colaborar com a imaginação do leitor, eles descrevem o local, sua estrutura e possibilidades. Os discursos parecem estanques, sem atualização. Não possuem informações atuais de exposições e eventos. Principalmente, no caso da Usina do Gasômetro, pode não espelhar a realidade do empreendimento que, conforme foi possível verificar posteriormente, parece não estar sendo aproveitado adequadamente.

Já os discursos do Tripadvisor, na maioria dos casos, utilizou um modo de organização enuncia- tivo, colocando seu ponto de vista em relação ao destinatário.

Como os dicursos oficiais não possuem identificação de editoria, os sujeitos enunciador e comunicante são, possivelmente, identificados como sendo uma mesma pessoa, a própria entidade governamental responsável pelo portal. Já nos discursos do site de viagens, os sujeitos enunciadores e comunicantes são previamente identificados como sendo a mesma pessoa, colocados, ao lado do comentário, todos os dados que possam caracterizá-lo como responsável por aquelas declarações. Na maioria dos discursos o TUd é o turista de passagem por Porto Alegre tanto no oficial quanto no Tripadvisor, mesmo que, neste último, os turistas podem ser segmentados por perfil.

Os dois discursos oficiais buscam informar aos interessados as principais características dos locais, mas usando estratégias diferentes para cada um. $O$ discurso do Brique utiliza a visada da incitação, procurando seduzir ao leitor para conhecer o ponto turístico. Já o discurso da Usina do Gasômetro, se dedica apenas a passar informações.

Sobre os contratos, pode-se verificar no quadro 1 (abaixo), que um tópico foi o mais abordado.

O principal contrato proposto pelos discursos abrange aspectos culturais. Os discursos não enfatizam belezas naturais e passam discretamente pelas qualidades arquitetônicas dos locais. $\bigcirc$ que impacta mais é a questão cultural dos locais.

\section{Considerações finais}

Atualmente, com todo o tipo de informações disponíveis na internet, não é possível iludir o tu-

Quadro 1 - Contratos

\begin{tabular}{|c|c|c|}
\hline & \multicolumn{2}{|c|}{ Brique da Redenção } \\
\hline Discurso oficial & Pluralidade cultural & Importância Cultural \\
\hline Tripadvisor 1 & Multicultural & Honestidade \\
\hline Tripadvisor 2 & Ótimo para Cultura & Aproveitar a oportunidade \\
\hline Tripadvisor 3 & Patrimônio Cultural & Honestidade \\
\hline
\end{tabular}


rista com belas fotos e discursos exaltando maravilhas dos locais, se não forem reais. $\bigcirc$ processo de escolha e definição do roteiro turístico passa por mais de uma fonte de informação.

A cidade não consegue mais forçar uma imagem somente pela mídia oficial. A imagem será composta pelo que vários indivíduos pertencentes à cadeia do Turismo dizem sobre ela. Aí estão os governos, secretarias, entidades, aparelhos turísticos e os próprios turistas.

No caso analisado, os discursos oficiais se dispuseram a descrever e qualificar os locais sem procurar convencer o leitor de que ele tenha que visitá-los. Como são descrições quase técnicas, não completam todas as informações que o turista pode desejar. Poucas fotos do local são publi- cadas no portal do turismo. As avaliações no Tripadvisor, apesar de serem feitas para que o avaliador consiga posições melhores e benefícios no site, ainda aparentam ser uma visão mais atual e real do local.

Mas o mais importante na definição da imagem da cidade na mídia digital, tanto no aspecto oficial quanto na visão do turista, é de que as atrações são importantes pelo seu aspecto cultural, pela relação da cidade com a cultura. Isso é enfatizado nos discursos oficiais e aceito pelos turistas como contrato no ato de comunicação, tanto que quando descrevem seu próprio discurso avaliativo, também procuram estabelecer contratos enfatizando aspectos culturais ou possibilidades de aproveitamento cultural do local. 


\section{Referências bibliográficas}

Prefeitura de Porto Alegre. Portal do Turista. Disponível em: http://www.portoalegre.travel/site/home.php. Acesso em: 14 de fevereiro de 2017.

Secretaria do Turismo de Porto Alegre. Turismo. Disponível em: http://www2.portoalegre.rs.gov.br/turismo/ default.php?p_secao=257.Acesso em: 14 de fevereiro de 2017.

CASTROGIOVANNI, Antonio Carlos. Turismo Urbano. São Paulo: Contexto, 2000.

CHARAUDEAU, Patrick. Linguagem e Discurso, modos de organização. São Paulo, SP: Contexto, 2014.

LYNCH, Kevin. A imagem da cidade. Lisboa: Edições 70, 1960.

Tripadvisor. Disponível em: www.tripadvisor.com.br. Acesso em: 16 de fevereiro de 2017.

URRY, John. O Olhar do Turista. São Paulo: Studio Nobel, 1990.

WAINBERG, Jacques. "Cidades como sites de excitação turística" In: Turismo Urbano, por Antonio Carlos CASTROGIOVANNI. Contexto, 2000. 